\title{
Torula Yeast in the Diet of Atlantic Salmon Salmo Salar and the Impact on Growth Performance and Gut Microbiome.
}

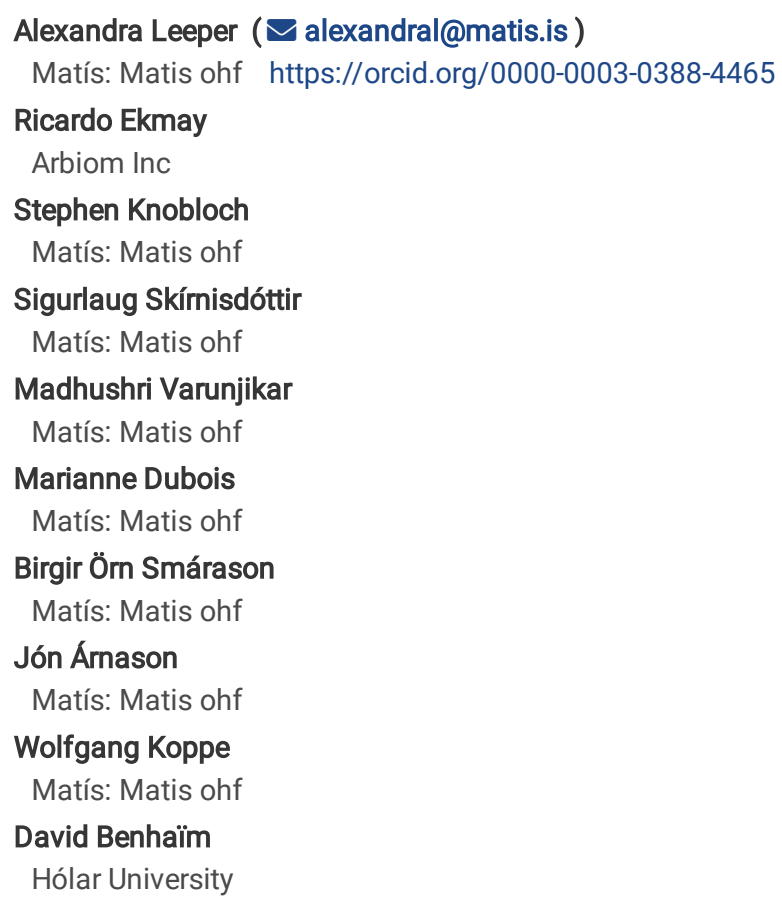

Research

Keywords: Lignocellulosic biomasses, Cyberlindnera jadinii, torula yeast, Atlantic salmon, aquaculture, gut microbiome.

Posted Date: June 8th, 2021

DOI: https://doi.org/10.21203/rs.3.rs-575053/v1

License: (c) (i) This work is licensed under a Creative Commons Attribution 4.0 International License. Read Full License 


\section{Abstract}

\section{Background}

Large scale Atlantic salmon (Salmo salar) aquaculture is expanding, and with it, the need to find suitable replacements of conventional protein sources used in formulated feeds. Torula yeast (Cyberlindnera jadinii) has been identified as a promising alternative protein for aquaculture feeds, and can be sustainable cultivated from lignocellulosic biomasses, contributing to circular economic growth. The present study aimed to investigate the impact of torula yeast on the growth performance and the gut microbiome of freshwater Atlantic salmon to facilitate the commercial uptake of this alternative protein. Two types of diets were assessed in this study. Firstly, a marine protein base diet where fish meal (FM) was replaced with increasing inclusion levels of torula yeast, $(0 \%, 10 \%, 20 \%)$ to provide a simplified replacement. Secondly, a marine protein and plant protein combination where mixed plant meals (MIX) were replaced with increasing inclusion levels of torula yeast, $(0 \%, 10 \%, 20 \%)$ to provide a commercial relevant dietary replacement.

Results

This study demonstrated that $20 \%$ torula yeast can replace fish meal without alteration to the growth performance while leading to potential benefits for the gut microbiome by increasing the presence of bacteria positively associated with the host. However, when torula yeast replaced a mix of plant meal in a combined protein source diet results suggest $10 \%$ inclusion of yeast produced the best growth performance results compared with both the control and $20 \%$ inclusion. At the highest inclusion level for the mixed diets potentially negative changes were observed in the gut microbial community, such as a decrease in lactic acid bacteria and an increased level of bacteria associated with slower growth in other salmonid species.

Conclusions

This study supports the application of torula yeast in the diet of Atlantic salmon as a partial replacement for conventional protein sources. However, the other components of the diet will need to be considered to determine the optimal inclusion level for this alternative protein. Future research should further optimise the inclusion of torula yeast in salmonid diets and investigate its influence on the functional role of the fish gut microbiome to facilitate improved formulated feed formulations and ensure a sustainable development of the aquaculture industry.

\section{Background}

Aquaculture production is set to play an increasingly important role in global food security (1). In Europe, Atlantic salmon (Salmo salar) aquaculture continues to grow in both market share and production intensity (2). Modern formulated feeds have developed from relying heavily on fish meal, primarily sourced from wild capture fisheries but have, through economic and environmental pressure evolved to incorporating large quantities of terrestrial plant protein sources such as soybean, rapeseed and corn meals (3). The scale of finfish production now necessitates the incorporation of alternative sources of dietary protein. The next generation of feed ingredients must meet the nutritional requirements of this carnivorous species, while alleviating both the market competition faced by terrestrial agriculture products and negating the adverse impact to growth and gut health attributed to anti-nutritional factors (ANFs) present in many plant ingredients (4).

Torula yeast (Cyberlindnera jadinni, anamorph name Candida utilis) has long been considered for animal feed, historically as a functional feed additive, and more recently in the research as a protein source $(5,6)$. Extensive existing research has investigated the potential to include torula yeast in diets of poultry (7), pigs (8-10), and a wide range of aquaculture species including, Pacific white shrimp (Litopenaeus vannamei) (11), Nile tilapia (Oreochromis niloticus) (12) and Atlantic salmon (S. salar) $(13,14)$. As a protein source, torula yeast has a high potential value since it can be cultivated independent of location and climate and does not add to pressure on existing agricultural systems (5). It can even be cultivated from side streams such as lignocellulosic biomasses, which are often low-value non-food wastage from other industries like forestry, producing materials of high protein content and value to aquaculture in a circular bioeconomic model (15-17). Research momentum is now increasing for yeast as a candidate to replace both fish meal and plant protein sources such as soybean meal in feed as demand for alternative protein sources rises (18,19).

The case for inclusion in aquaculture feeds including those designed for Atlantic salmon ( $S$. salar) is compelling. Torula yeast has an appropriate protein content and a similar but not identical amino acid profile to fish meal $(5,15,20)$. In freshwater stage Atlantic salmon of start weight $28 \mathrm{~g}$, torula yeast has successfully replaced up to $40 \%$ of the crude protein from fish meal compared with a control of $58 \%$ fishmeal without negative impact to growth performance (18). Torula yeast has displayed beneficial functional properties such as a reduction in inflammation of the distal intestine during smoltification, a crucial developmental period for Atlantic salmon (14). Torula yeast has also been associated with immune-modulating benefits which could greatly enhance their value to the aquaculture industry (21). However, a significant research gap exists in optimising and standardising the dietary inclusion levels which is necessary to facilitate commercial adoption of this alternative protein (22).

The gut microbiome of cultured fish species is now understood to play a key role in many aspects of host health and welfare, affecting immune development (23), disease resistance (24), growth (25), digestion and nutrient uptake $(26,27)$. There are multiple factors that influence the establishment and final composition of the gut microbiome in farmed Atlantic salmon ( $S$. salar), one key factor is the diet of the host (25,28,29), additional important factors include, the life stage of the fish and the surrounding environment $(30,31)$. Consequently, it is important to consider changes to gut microbiome composition and their potential consequences when investigating the suitability of new and alternative feed ingredients

Page $2 / 20$ 
for aquaculture (32). The gut microbiome during early life stages of fish and the impact of changing diet is of particular interest since it can influence the development of host adult gut microbiome and therefore overall host development $(33,34)$ although, during these early stages, the gut microbiome is also considered to be highly malleable to dietary influence $(35,36)$. The research has established that the presence of certain bacteria have functional benefits to the fish host, for example, Lactic Acid Bacteria (LAB) and Bacilli (37), whereas dysbiosis or an unbalanced microbial community is associated with undesirable conditions and consequently, poor health $(38,39)$.

When plant protein replaces or partially replaces marine protein in salmonid diets, it is established that the gut microbiome is significantly altered. Research shows that pea protein replacing $10 \%$ fish meal drove an increase in Streptococcus, Leuconostoc, Weissella, which all belong to LAB group of bacteria (29), and mixed plant meals replacing to $97 \%$ mixed animal and marine meals drove communities with more Lactocaillales, Bacillales and Pseudomonadales, compared with Bacteroidales, Clostridiales, Vibrionales, Fusobacteriales and Alteromonadales (35) in juvenile Rainbow Trout (Oncorhynchus mykiss). Atlantic salmon (S. salar) post-smolts fed $30 \%$ inclusion levels of soybean meal and soy protein concentrate had higher relative abundances of LABs than those fed a fish meal diet (32). When the yeasts, Saccharomyces cerevisiae and Wickerhamomyces anomalus replaced $40 \%$ and $60 \%$ of fish meal in Rainbow trout (O. mykiss) there was a significant alteration of the gut microbiome, whereas, $20 \%$ S. cerevisae did not alter the community (40). There exists a gap in the literature clarifying how torula yeast affects fish gut microbiome despite the growing interest in this protein for dietary inclusion and this is important to characterise the impact of this alternative ingredient for the aquafeed industry (5). In pig diets, torula yeast was associated with selection for Lactobacillus spp. in the gut microbiome (41)

The aim of the present study was to investigate the effect of replacing ingredients currently used in salmonid feeds with increasing inclusion of torula yeast (C. jadinni) on both growth performance and the microbiota present in the gastro-intestinal tract of juvenile Atlantic salmon ( $S$. salar). To optimise this characterisation and provide a comprehensive investigation two basal diets were considered. The first of which was a marine proteinbased diet where fish meal (FM) was replaced with increasing levels of torula yeast to provide a simplified replacement. The second of which was a marine protein and plant protein combination where a mixture of plant meals (MIX) was replaced with increasing levels of torula yeast to provide a commercial relevant dietary replacement. These two basal diets were formulated separately thus, will be investigated here separately.

\section{Methods}

\subsection{Experimental animals and study design}

Atlantic salmon (S. salar) hatching on 31 October 2018 were reared at $5.5^{\circ} \mathrm{C}$ by Stofnfiskur Ltd. (Iceland). Eyed eggs were transferred to Laxar ehf. (Iceland) where they were raised to first feeding using standard commercial techniques and commercial start-feed diet BioMar Inicio-plus (United Kingdom) of $0.5 \mathrm{~mm}$ pellet size. Fry were transferred to Matís Aquaculture Research Station (MARS) on 23 January 2019 , where they were acclimated for one week to the study facilities. All fish within the experiment were individually weighed following a 12-hour fasting period under anaesthetic (2phenoxyethanol of $300 \mathrm{ppm})$. All fish were very close in weight at the beginning of the feeding trial $(1.14 \pm 0.1 \mathrm{~g})$. Fish were split into eighteen $20 \mathrm{~L}-$ white circular PVC tanks, in triplicate for each feed treatment. Each tank contained 20 individual fish. Fish were kept in freshwater at $9.5 \pm 0.5^{\circ} \mathrm{C}$ under 24-hour photoperiod of $20 \pm 4$ lux, oxygen levels were maintained above $80 \%$ saturation. Fish were fed with the experimental feed treatments for 35 days continuously. The experiment was performed following European and Icelandic guidelines and within the permits and licences of the MARS facility as described in the Declarations of this manuscript.

\subsection{Production of torula yeast}

Dried, inactive torula yeast (C.jadinii) was cultivated by RISE Processum (loc) on wood hydrolysates provided by Arbiom Inc. (Durham, NC, USA). Briefly, wood hydrolysates were generated from hardwood chips (mixed species) locally sourced from Virginia, USA. Subsequently, the hydrolysates were fermented in a 50-L reactor under continuous operation followed by washing, thermal inactivation, and drying to produce the final product.

\subsection{Experimental feed treatments and feeding}

There were two basal diets formulated for this investigation. In the first basal diet group there were three treatments with a marine protein base, providing a simplified replacement where fish meal (FM) was increasingly replaced with torula yeast with inclusion levels $0 \%$ (FM00), 10\% (FM10), and $20 \%$ (FM20) (Table 1). In the second basal diet group there were three treatments with a marine protein and plant protein combination base, providing a commercially relevant replacement, where a plant protein mixture (MIX) was increasingly replaced with torula yeast with inclusion levels $0 \%$ (MIX00), 10\% (MIX10), and 20\% (MIX20) (Table 2). The chemical composition of all protein sources used in feeds for this experiment from both FM and MIX basal diets are presented (Table 3). The feed treatments were produced by cold pelleting at Matís ohf. (Iceland), with a pasta machine (ADE, Germany). All dry ingredients were milled to bring all materials to equal particle size (IPHARMACHINE, Germany). Dry ingredients were then homogenised in a standard food mixer (KitchenAid, USA) and the mix was put back through the same mill to improve the homogeneity of the feed. The dry mix was returned to the food mixer and fish oil was added while simultaneously mixing, a small volume of water was added to produce the ideal consistency for the next stage $(200 \mathrm{ml})$. The mix was then processed in the pasta machine to produce $0.5 \mathrm{~mm}$ pellets. These pellets were dried in a commercial food dryer (Kreuzmayr, Austria) to $<10 \%$ moisture content. Resulting feed treatments were analysed for chemical composition (Table 1

Page $3 / 20$ 
FM, Table 2 MIX). During the 35-day feeding trial, tanks were fed 5 times per day by electric belt-feeder between the hours of 08:00 to 20:00. All tanks were fed identical volumes, with $15 \%$ excess based on feed requirements at this developmental stage.

\subsection{Growth Performance}

After 35 days of continuous feeding all individual fish from all FM and MIX tanks were weighed (wet weight (g)) and measured (total length (cm) following a 12-hour fast. From this data the Fulton's Condition Factor (K) and Specific Growth Rate (\%) (SGR) over the study period could be calculated: $\mathrm{K}=\left(\right.$ Weight/Total Length $\left.{ }^{3}\right) \times 100$ and SGR $=(($ Ln(Final Weight) - Ln(Initial Weight $\left.)) \times 100\right) / t$, where is the number of days over which the trial was run. Mortality was monitored daily throughout the feeding trial.

\subsection{Gut Sampling}

After the growth performance assessment, all fish were left for one week to recover from handling and fed with the respective FM and MIX feed treatments. At the end of this week fish were fasted for 12 hours and then randomly sampled, three (3) fish from each tank, nine (9) fish per feed treatment for FM and MIX diets respectively. Sampled fish were euthanised with a lethal dose of anaesthetic (phenoxyethanol) 600ppm and the outside of the fish was rinsed in $90 \%$ ethanol followed by sterile distilled water. The gastro-intestinal tract from the top of the mid-gut, just below the pyloric caeca down to the end of the distal gut was directly removed under sterile conditions, with any content present included. Samples were then stored at $-80^{\circ} \mathrm{C}$ prior to downstream processing.

\subsection{DNA extraction, $P C R$ amplification and sequencing}

Gut samples were individually homogenised manually using a sterile petri dish with a sterile scalpel to break up the gut sample. Samples were transferred to a sterile $2 \mathrm{ml}$ Eppendorf tube with $300 \mu \mathrm{l}$ of sterile $1 \mathrm{~mm}$ diameter sterile silica beads (BioSpec Products, United States). $800 \mu \mathrm{l}$ of CD1 solution from the QIAamp PowerFecal Pro DNA kit (QIAGEN, Germany) was added to the Eppendorf tube. Samples were vortexed for 5 seconds and shaken at maximum speed $(30 \mathrm{~Hz})$ in a laboratory mixer mill (Retsch MM400) for 1 minute. The supernatant ( 800 $\mathrm{\mu l})$ was transferred to the PowerBead Pro Tube from the QIAGEN QIAamp PowerFecal Pro DNA kit. The protocol for this DNA extraction kit was then followed and finally DNA was eluted with $80 \mu \mathrm{l}$ of $\mathrm{C} 6$ solution. An empty sample with no material was also run to ensure no contamination occurred during the DNA extraction protocol. DNA concentration was measured using $2 \mu$ l of sample in the Invitrogen Qubit dsDNA BR Assay kit (Invitrogen, Carlsbad, CA, USA) which measure samples with DNA concentration from 2-1000ng. DNA were diluted to $4 \mathrm{ng} / \mu \mathrm{l}$ in a $50 \mu \mathrm{l}$ aliquot. Samples were then subjected to PCR of a region covering V3-V4 regions of the 16S rRNA gene with a universal bacterial primer pair S-D-Bact-0341-b-S-17 (5'-CCTACGGGNGGCWGCAG-3')/S-DBact-0785-a-A-21(5'-GACT- ACHVGGGTATCTAATCC-3') (42). The PCR master mix included the diluted DNA, nuclease-free water, Q5 High-Fidelity DNA polymerase (New England Biolabs, Ipswich, USA), Q5 GC Enhancer, 0.5 $\mathrm{M}$ of each primer containing Illumina overhang adapters, and 1x Q5 Reaction buffer, $200 \mu \mathrm{M}$ dNTPs (New England Biolabs, Ipswich, USA). Included in the PCR were both positive and negative samples to monitor for successful amplification and absence of contamination of the target region only. The thermocycling protocol had an initial denaturation step ( $98^{\circ} \mathrm{C}$ for $\left.30 \mathrm{~s}\right)$, then 35 cycles of, denaturation $\left(98^{\circ} \mathrm{C}\right.$ for $\left.10 \mathrm{~s}\right)$, annealing $\left(52^{\circ} \mathrm{C}\right.$ for $\left.30 \mathrm{~s}\right)$, and extension $\left(72^{\circ} \mathrm{C}\right.$ for $\left.30 \mathrm{~s}\right)$, with a final extension $\left(72^{\circ} \mathrm{C}\right.$ for $\left.2 \mathrm{~min}\right)$. Libraries were multiplexed with Nextera XT v2 barcodes (Illumina, USA), normalised using Sequel-Prep Normalisation Plates (ThermoFisher Scientific, USA) then sequenced on a MiSeq desktop sequencer (Illumina, USA) using v3 chemistry and $2 \times 300$ cycles.

\subsection{Statistical Methods}

\subsubsection{Growth performance}

Statistical analyses were performed in R version 3.6.1 (2019-07-05). All tests were two-tailed with a significance level set to $a=0.05$. FM diet and MIX diets were considered separately since they were formulated independently but identical statistical designs were used.

For growth performance, two dependent variables were statistically assessed, Condition Factor (K) and Specific Growth Rate (SGR (\%)). A Generalised Linear Mixed Model (GLMM) model was assessed first with the package Ime4 (43), where Feed Treatment was considered a fixed factor and Tank replicate was considered a random nested factor of Feed Treatment. For both FM and MIX diets the Tank replicate did not have a significant effect. Therefore, a Generalised Linear Model (GLM) with the package nlme (44) was selected where for FM and MIX diets respectively Feed Treatment was a fixed factor and tank effect was not significant. Tukey post-hoc testing was applied to results with significant output.

\subsubsection{Gut microbiome}


Demultiplexed FASTQ files from Illumina were processed to produce Amplicon sequence variants (ASVs) using the DADA2 package version 1.16.0 (45)

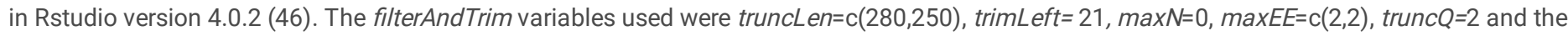
learnError function was performed on a subset of 105888913 reads. The SILVA database version 138 was used to assignTaxonomy to the ASVs (47). The microbial community was analysed using R packages phyloseq (48), microbiome (49) and vegan (50), and visualised with ggplot2 (51). The number of reads output from the DADA2 pipeline were $15449.44 \pm 3575.3$ for fish meal-based diets and $13317.48 \pm 3341.2$ for mix meal-based diets. PCR and DNA negative control samples were included in the sequencing and dada2 pipeline to check for potential contamination of samples, there was no detectable contamination in these control samples. For comparison the read depth was normalised across samples with the function rarefy_even_depth to the sample with the lowest read depth. ASVs from the Kingdom Eukaryota, Order Chroloplast and Family Mitochondria were removed from downstream analysis as they are often remnants from 16S fragments in Eukaryotes and do not belong to the bacteria. Raw $16 \mathrm{~S}$ rRNA gene amplicon reads are deposited in the Sequence Read Archive under BioProject PRJNA732903.

The microbiome community for MIX and FM basal diets were quantitatively analysed using alpha and beta diversity measures. The selected alpha diversity measures where the observed richness of AVSs, Shannon diversity, Chao1 diversity and Pielou's Evenness. A General Linear Mixed Model (GLMM) was used to assess if there was a significant difference in these alpha diversity measures between the different Feed Treatments from the FM and MIX diets respectively. In this model Feed Treatment was a fixed factor and Tank was a nested random factor of feed treatment. The random nested factor of Tank was tested by a Likelihood Ratio Test (LRT) (52). Post-hoc testing was carried out using Tukey test. The microbiome community assemblage for each of the feed treatment types were transformed using a Bray-Curtis dissimilarity matrix and non-metric multidimensional scaling was applied. An Analysis of similarity (ANOSIM) test was applied to assess for significant difference between and within fish fed different Feed Treatments in the fish meal-based feed and the mix-meal based feeds respectively. To further investigate the microbiome community assemblage the relative abundance as a proportion was visualised at the phylum level in stacked bar plots for direct comparison. The genus level was then visualised, with all genera present at less than $1 \%$ abundance amalgamated into a category called other and the genera present at greater than $1 \%$ abundance were visually displayed using boxplots for each feed treatment in the fish meal-based and mix-meal based treatments respectively.

\section{Results}

\subsection{Growth Performance}

For FM basal diets, Specific Growth Rate (\%) (SGR) was not significantly different between the three inclusion levels of torula yeast with very similar average values and standard deviations (FM00:1.09 \pm 0.42 , FM10: 1.09 \pm 0.37 , FM20: 1.13 \pm 0.39 ) (Figure 1a). For MIX basal diets, MIX10 had the highest SGR\%. There was a significant difference in SGR \% between MIX10 treatment and the highest inclusion MIX20. But there was no significant difference between the control MIX00 and either MIX10 or MIX20 (MIX00: 1.12 \pm 0.39 , MIX10: 1.22 \pm 0.38, MIX20: 1.03 \pm 0.46 ) (Figure 1b).

For FM basal diets, the Condition Factor $(K)$ was not significantly different between the three inclusion levels (FM00: $0.85 \pm 0.10, F M 10: 0.86 \pm 0.06$, FM20: 0.88 \pm 0.09 ) (Figure 1c). For MIX basal diets, the Condition Factor (K) was not significantly different between the three inclusion levels (MIX00:

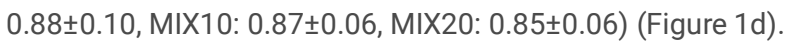

\subsection{Gut Microbiome}

For FM basal diets, no significant differences were detected in any of the alpha diversity measures tested across the three inclusion levels of torula yeast. While not significant, FM10 fish did have a higher average value for Observed diversity (Figure 2a), Shannon diversity (Figure 2b), and Chao1 diversity (Figure 2c) than other inclusion levels but for Pielou's evenness than FM20 which had the greatest community evenness (Figure 2d). For MIX basal diets, three of the alpha diversity measures were significantly different. For the Observed diversity (Figure 3a), Shannon diversity (Figure 3b) and the Chao1 diversity (Figure 3c), there was a significantly lower value for MIX20 than in the control, MIX00. There was no significance in the Pielou's evenness between the three inclusion levels (Figure 3d).

The microbial community composition for FM basal diets, were significantly different between all inclusion level, with greater difference between inclusion level than within it, ANOSIM P=0.001 R=0.2234 (Figure 4a). For MIX basal diets, the microbiome community composition was significantly different between inclusion levels and there was a great difference between inclusion level than within it, ANOSIM P=0.003 R=0.1097 (Figure $4 \mathrm{~b}$ ). At the phylum taxonomic level for the FM diets, the gut microbiome was dominated by Firmicutes for all inclusions of torula yeast (FM00=75.4\% \pm 6.3 , $\mathrm{FM} 10=85.54 \% \pm 1.8, \mathrm{FM} 20=67.43 \pm 20.6)$. The second and third most dominate phyla for all inclusions were Actinobacteria (FM00 $=9.28 \pm 6.6$, FM10 $=11.14 \pm 2.1, F M 20=13.60 \pm 5.4$ ) and Proteobacteria (FM00=3.07 $\pm 2.6, F M 10=2.44 \pm 2.2, F M 20=13.11 \pm 17.5$ ) respectively. All other phylum occurring were present at $1 \%$ or lower relative abundance (Figure 5). At the phylum taxonomic level for the MIX basal diets, the gut microbiome was dominated by Firmicutes for all inclusions of torula yeast (MIX00 $=75.73 \pm 13.2, \mathrm{MIX} 10=77.58 \pm 10.2, \mathrm{MIX} 20=73.78 \pm 13.5)$. The second and third most dominate phyla for all inclusions were Actinobacteria (MIX00=10.82 $\pm 1.9, \mathrm{MIX} 10=14.08 \pm 5.5, \mathrm{MIX} 20=11.9 \pm 5.8)$ and Proteobacteria $(\mathrm{MIX} 00=5.62 \pm 2.5$, MIX10=4.27 $\pm 3.4, \mathrm{MIX} 20=6.36 \pm 9.0$ ) respectively (Figure 5). 
At the genus taxonomic level for the FM diets the genus Staphylococcus had the highest relative abundance, and abundance was lowest in FM20 compared with FM10 and FM00. For Clostridium_sensu_stricto1, Leuconostoc, Preptostreptococcus and Paeniclostridium, there is a pattern of greater average relative abundance in the FM10 inclusion level than both FM00 and FM20. The opposite trend was observed for Sporanaerobacter, Paraclostridium and Clostridium_sensu_stricto7 which average relative abundance was slightly lower in FM10 compared with FM00 and FM20. There was decreasing presence of Tepidmicrobium with increasing inclusion of torula yeast. There was a similar average relative abundance of Weisella for inclusion levels but with a slight increasing trend with increasing torula yeast inclusion (Figure 6). At the genus taxonomic level for the MIX diets the genus Staphylococcus had the highest relative abundance, and the average relative abundance increased with increasing inclusion of torula yeast, as did the average abundance of Weissella. Conversely, there was a trend of decreasing presence of Lactobacillus with increasing inclusion.

Corynebacterium was highest in MIX10, and Sporanaerobacter was lowest in the same inclusion. Tepidmicrobium and Clostridium_sensu_stricto_1 were highest in MIX20. Whereas, for Peptostreptococcus, Paraclostridium and Leuconostoc they were lowest in MIX20. There were similar levels of Clostridium_sensu_stricto_7 at all inclusion levels (Figure 7).

\section{Discussion}

The existing literature has established the potential of torula yeast as a valuable protein source for the aquafeed industry $(15,18)$. The present study addressed essential knowledge gaps regarding the effect of replacing ingredients currently used in salmonid feeds with increasing inclusions of torula yeast on both growth performance and gut microbiome of freshwater stage Atlantic salmon (Salmo salar). Two separate base diets were investigated A marine protein base diet where fish meal (FM) was replaced with increasing levels of torula yeast to provide a simplified replacement and a marine protein and plant protein combination where mixed plant meals (MIX) were replaced with increasing levels of torula yeast to provide a commercial relevant dietary replacement.

Growth performance for fish fed the FM diets was comparable between all inclusion levels for both the Specific Growth Rate SGR (\%) and Condition Factor (K) up to $20 \%$ inclusion. This matches well with existing research where torula yeast has successfully replaced up to $40 \%$ of protein from fish meal in the diets of freshwater (FW) Atlantic salmon without negatively impacting growth performance (18). Existing research suggests that the addition of torula yeast to a standard fish meal diet can even enhance the growth of FW Atlantic salmon compared to fish meal alone (13). The present study provides further evidence that even in Atlantic salmon less than $2 \mathrm{~g}$ body weight, torula yeast is a suitable partial replacement for marine protein. The lack of difference in $\mathrm{K}$ across the different inclusion levels suggest torula yeast also provides comparable energy levels to marine protein (53). Growth performance for fish fed MIX diets was best for fish fed the moderate inclusion MIX10, even better than both the control and the highest inclusion level, and $\mathrm{K}$ was comparable across all diets. Few studies have explored the replacement of plant proteins with torula yeast despite the prevalence of these materials in commercial salmonid. The reduced growth performance of fish fed the MIX20 compared with MIX10 was also found when torula yeast replaced gluten and starch in a soybean meal-based diet also at an inclusion of 20\% (13) however MIX20 was comparable with the MIX00 control, suggesting MIX10 may be optimal in this juvenile study. In comparison, when $25 \%$ inclusion level of torula yeast replaced a mixture of plant and marine protein sources in Atlantic Salmon through the freshwater to seawater transfer, growth performance and feed intake were improved compared to the control (14). This difference in results could be due to the strain and growing conditions suggesting this process can be optimised to improve the application for salmonids (18). In an experiment with Tilapia (Oreochromis mossambicus) fed a mixed diet with both animal, and plant protein combined, increasing levels of torula yeast were fed to fry, and showed similar trend to this study, with moderate levels, in this case $30 \%$ torula yeast supporting better growth than lower or higher levels (54). This study suggests that there is potential for growth benefits with moderate inclusion levels of torula yeast as a replacement for plant protein. The decline in growth performance at higher inclusions levels could be driven by potential over-feeding of yeast presenting a detrimental impact (22) however given that the higher inclusion is comparable with the control, a detrimental impact is unlikely in this study. This is supported by good growth performance of the $20 \%$ inclusion for the FM in this study. However, this study along with (Øvrum Hansen) et al., 2019, indicates that higher inclusion levels of torula yeast are more applicable in combination with a marine protein diet than they are with a mixed source protein diet, but that the strain and growth conditions could be improved to optimise utilisation in mixed diets (18).

The gut microbiome of fish fed FM diets and MIX diet is altered by the replacement of proteins with torula yeast, but the impact trends differ for the different dietary bases. The lack of difference in alpha diversity measures between any of the FM diets suggests that all three diets provide a comparable substrate to support a community with similar defining characteristics, however the actual community composition established is different, which is shown by the beta diversity, and this is most apparent at the genus level. The MIX diets support gut microbiome communities with different alpha diversity characteristics, especially for the highest inclusion level MIX20 and with different community compositions between the three inclusion levels which are also most clear at the genus level. Compared to the existing literature on the Atlantic salmon (Salmo salar) gut microbiome during the freshwater stage, the alpha diversity measures for both the FM and MIX fish in this study fall within normal levels for captive individuals (55). The alpha diversity results of FM diets concur with comparable experiments with other salmonid species. In Rainbow trout (Oncorhynchus mykiss) kept in freshwater up to $20 \%$ replacement of fish meal with the yeasts Saccharomyces cerevisiae and Wickerhamomyces anomalus did not significantly alter the gut microbial community diversity, but higher replacement levels of $40 \%$ and $60 \%$ reduced bacterial diversity, and even led to increasing presence of the pathogenic Candida albicans at $60 \%$ inclusion levels, even reducing the presence of LABs (40). This suggests that inclusion of greater than $20 \%$ of yeasts may be problematic for salmonid health which could in turn affect production even when in combination with marine protein only (22). To the knowledge of these authors this is the first experiment to assess the gut microbiome of Atlantic salmon when plant proteins in a mixed protein source diet are replaced with a yeast protein source, yet this is a highly relevant concern for commercial salmonid aquaculture. This study reveals that the impact to the alpha diversity is more pronounced than in marine protein diets for observed diversity, Shannon diversity and

Page 6/20 
Chao1 diversity which were all higher in the $0 \%$ control and moderate $10 \%$ inclusion of torula yeast than in the higher inclusion of $20 \%$ in the MIX diets. Higher levels of alpha diversity measures do not necessarily mean a healthier or more resilient community assemblage, so we must take this outcome in context with the other findings about the gut microbiome community discussed here (56). In early stage Rainbow trout (Oncorhynchus mykiss) alpha diversity measures decreased when animal protein was replaced with a mix of plant proteins, but plant proteins levels were at $50 \%$ and $97 \%$ replacement (35) which were much higher than in the present study. This indicates drastic changes in diet can be detected in the alpha diversity measures, suggesting that replacing plant proteins with torula yeast in our MIX diets drastically influenced the community, more than replacing fish meal in a marine protein diet for our FM diets. In another monogastric animal, weaning pigs, a 40\% replacement of conventional proteins (a combination of plant and marine proteins) with torula yeast (Cyberlindnera jadinii), both the alpha diversity and the beta diversity were significantly altered by the replacement, with lower alpha diversities with the $40 \%$ diet (41), suggesting a similar trend as found in the present study for the MIX diets.

Existing research on the gut microbiome of freshwater Atlantic salmon suggests that even when alpha diversity is not altered, difference may be present in the beta diversity, for example, Chao1 richness and Shannon diversity were not altered by acute cold stress or a chronic environmental stress but the beta diversity was altered (57). In early stage salmonids when the dietary protein composition is altered, existing studies observed a significant shift in the beta diversity and composition of the gut microbiome, in Atlantic salmon (Salmo salar) (58), in Rainbow trout (Oncorhynchus mykiss) $(35,59)$, and in Arctic charr (Salvelinus alpinus) (60). Similarly, in the present study, beta diversity was distinct between each inclusion level of torula yeast irrespective of the dietary base (FM or MIX) and which protein component was being replaced. Since gut microbiota changes between freshwater and seawater transfer (31), future studies should follow Atlantic salmon fed torula yeast as a dietary protein through-out development, from first feeding to harvest to clarify the impact across different environmental conditions. In other cultured fish species, the presence of yeast species either as a supplement or as a protein replacement for conventional proteins also significantly altered the community compositions, in earlystage zebrafish (Danio rerio) (33), in the gilthead sea bream (Sparus aurata) (61) and the grass carp (Ctenopharyngodon idellus) (62).

The gut microbiome composition of early stage Atlantic salmon in this study for both FM and MIX diet bases was similar at the phylum level regardless of the torula yeast inclusion level. Similarly in other studies that have used next generation sequencing in salmonids during the freshwater growth stages, the dominance of Firmicutes followed by Proteobacteria have been noted with varying levels of Actinobacteria depending on the study $(31,40,63,64)$. Suggesting that at lower taxonomic resolution a core phyla composition can be expected regardless of diet and influenced by a range of other factors. The drivers of differing community compositions can be seen in this study at the genus level. The dominance of Firmicutes at the phyla level for both FM and MIX diets at all inclusion levels is explained by the high relative abundance of Staphylococcus at the genus level. This dominance of Staphyloccocus species is consistent with other Atlantic salmon (Salmo salar) and many other fish gut microbiome characterisations $(65,66)$ and it has been associated with nutritional processes in the salmonid, Arctic charr (Salvelinus alpinus) (67). However, this study revealed different trends for FM and MIX diets with increasing inclusion of torula yeast further suggesting that torula yeast interacts differently with marine protein diets and mixed source protein diets, this could be to do with potentially differing levels of dietary fibre in FM based diets and the MIX diets in this study. Torula yeast has a high (20\%) Total Dietary Fibre (TDF) at $20 \%$ TDF, which is higher than standard fish meal which is largely devoid of TDF but may see values as high as $5 \%$ (68), which may explain why we see a slight trend toward increased diversity indices with increasing torula yeast inclusion, although the effect is minimal. Conversely in the MIX diets, a similarly high TDF\% from the combined plant meals (68) is being replaced by the torula yeast. This suggests that TDF is not the only driver of the decreased diversity indices seen for the high yeast MIX20 diet. The torula yeast was $12 \%$ insoluble fibre and $8 \%$ soluble fibre (20\% TDF) (R.Ekmay 2021 , personal communication 26 May). Future investigations should assess the balance of soluble and insoluble fibre components of formulated feeds with torula yeast and their impact on fish gut microbiota since dietary fibre is known to influence microbiome in other animals (69). It will be important to elucidate the significance of such differing trends for health and development of cultured salmonids. The Lactic Acid Bacteria (LABs) from the genus Weissella and Leuconostoc (37) did not show a strong trend in the FM diets, but slightly increased with increasing inclusion of torula yeast. Conversely, for the MIX diets, the LABs Lactobacillus, Leuconostoc, and Weissella (37) were present, and for the former two they declined with increasing inclusion of torula yeast, whereas the latter increased slightly in the presence of torula yeast. In the fin-fish literature, LABs are widely regarded to be linked to positive benefits such as disease resistance, improved performance and are associated with innate immune activities $(37,70)$, however the exact impact is dependent on the species of bacteria and the specific host. In the FM diets of this study Clostridium_sensu_stricto_1, and Preptostreptococcus were both higher in diets containing torula yeast, and highest in the modest $10 \%$ inclusion. These genera (Clostridium and Preptostreptococcus) have been associated with faster growth in Rainbow trout (Oncorhynchus mykiss) faecal bacteria samples, although in our study Clostridium_sensu_stricto_7 did not show a strong trend. However, the genus Paeniclostridium was associated with slower growing individuals (71) and this was also highest in FM10 of the fish from this study presenting a complicated picture. Since the growth was not significantly different in the FM diets of this study, it might suggest that Atlantic salmon (Salmo salar) may have different bacterial indicators of growth than other salmonids. In the MIX diets the genus Corynebacterium was lowest in the moderate $10 \%$ inclusion of torula yeast, and highest in the $20 \%$ inclusion level, and in Rainbow trout (Oncorhynchus mykiss) this genus was associated with slow growing individuals (71) which does correspond with the growth results for the present study of Atlantic salmon (Salmo salar), suggesting it may be a potentially useful indicator for this salmonid species. It would be highly valuable for future research to identify bacteria in the digestive tract of Atlantic salmon that are associated with fast and slow growing individuals.

It appears from this study that when torula yeast can effectively partially replace FM based diet up to an inclusion of $20 \%$ without apparent negative impact to the gut microbiome community assemblage, and some potential benefits in terms of raising the levels of some LABs. Conversely, when torula yeast is added to a mix of protein sources it is more effective for growth performance and promoting desirable gut bacteria at moderate levels

Page $7 / 20$ 
of $10 \%$ inclusion than at the higher inclusion level of $20 \%$. The finding that moderate levels of torula yeast in a mixed protein diet are preferable to higher inclusions is reflected in the existing literature for Atlantic salmon (Salmo salar) (21). It should be noted that this study sampled the gut digesta and mucosa together, which may have masked further differences in the gut microbiome community composition, since the digesta appears most impacted by diet. Future studies should focus on the digesta where possible (32) although this has proved challenging with very small Atlantic salmon (Salmo salar), it would be valuable to investigate the gut microbiome down to the species taxonomic resolution. Additionally this early developmental stage in the salmonid life cycle is a time of a highly dynamic gut microbiome that is malleable and has the potential to change when the dietary input changes and may not be consistent or have consistent function over time $(30,35)$.

\section{Conclusions}

Torula yeast (Cyberlindnera jadinii) has been identified as a promising alternative protein for Atlantic salmon (Salmo salar) aquafeeds. This study has demonstrated that during the freshwater growth stage, torula yeast can partially replace conventional proteins in formulated feeds, but that the optimal level of inclusion may be dependent on the total dietary composition and the types of proteins that are being replaced. In a marine protein diet, this study revealed that $20 \%$ torula yeast can be included as a replacement for fish meal without altering growth performance and with possible benefits for gut microbial community such as an increase in some lactic acid bacteria. Comparatively, in a commercially comparable diet that combines marine protein and plant proteins, a $10 \%$ inclusion of torula yeast supported better growth performance than the control. At higher inclusion levels of $20 \%$ there were no growth benefits and potentially negative changes to the gut microbiome, such as a decrease in LABs and increasing levels of bacteria associated with slower growth in other salmonid species. It will be important in future research to understand why torula yeast inclusion produces different results in combination with different dietary proteins and to investigate the potential links between changes in the gut microbiome with growth and resilience in Atlantic salmon.

\section{Declarations}

\section{Ethics approval and consent to participate}

The trial was carried out under the licence FE-1134 (Rekstrarleyfi) from MAST and UST201707 (Starfsleyfi) from the Icelandic Environment Agency.

\section{Consent for publication}

Not applicable

\section{Availability of data and material}

The datasets generated for gut microbiome during the current study are available in PRJNA732903 repository, http://www.ncbi.nIm.nih.gov/bioproject/732903. Additional datasets used during the current study are available from the corresponding author on reasonable request.

\section{Competing interests}

R. Ekmay is employed by Arbiom Inc., a company that develops and markets torula yeast. All other authors declare that they have no competing interests.

\section{Funding}

This project was funded under the SYLFEED project H2020-BBI-JTI-2016 project number: 745591 . The funding body did not have any role in the design of the study, collection, analysis and interpretation of data or in the writing of the manuscript.

\section{Authors' contributions}

$\mathrm{AL}$ conducted the trials, carried out lab work and analysed all data and lead the writing of this manuscript. RE coordinated the production and processing of torula yeast, provide nutritional expertise and contributed to writing and editing of this paper. SK provided expert advice and practical support in gut microbiome sample processing and analysis. SS provided expert advice and practical lab support for gut microbiome sample processing. MV supported animal husbandry and development of gut microbiome protocols. MD supported animal husbandry and development of gut microbiome protocols. BÖS co-ordinated SYLFEED project management and reporting and supported experimental design. JA co-ordinated SYLFEED project management and reporting and supported experimental design and feed formulation, WK provided nutritional expertise and 
supported experimental design. DB contributed to writing and editing this manuscript and provide experimental, analytical and academic support. All authors read and approved the final manuscript.

\section{Acknowledgements}

The authors would like to acknowledge the contribution of all microbiology and aquaculture lab staff at Matís that contributed to the successful running of this experiment and collection of data. Thanks also go to the aquaculture research team at the Norwegian University of Life Sciences, Norway for advice and academic support.

\section{References}

1. Subasinghe R, Soto D, Jia J. Global aquaculture and its role in sustainable development. Rev Aquac. 2009 Mar 1;1(1):2-9.

2. FAO. The State of World Fisheries and Aquaculture 2020. 2020. 200 p.

3. Gatlin DM, Barrows FT, Brown P, Dabrowski K, Gaylord TG, Hardy RW, et al. Expanding the utilization of sustainable plant products in aquafeeds: A review. Vol. 38, Aquaculture Research. John Wiley \& Sons, Ltd; 2007. p. 551-79.

4. Krogdahl Å, Penn M, Thorsen J, Refstie S, Bakke AM. Important antinutrients in plant feedstuffs for aquaculture: An update on recent findings regarding responses in salmonids. Aquac Res. 2010 Feb 1;41(3):333-44.

5. Agboola JO, Øverland M, Skrede A, Hansen JØ. Yeast as major protein-rich ingredient in aquafeeds: a review of the implications for aquaculture production. Rev Aquac. 2020 Sep 19;raq.12507.

6. Jones SW, Karpol A, Friedman S, Maru BT, Tracy BP. Recent advances in single cell protein use as a feed ingredient in aquaculture. Vol. 61, Current Opinion in Biotechnology. Elsevier Ltd; 2020. p. 189-97.

7. Cruz A, Sterten H, Steinhoff FS, Mydland LT, Øverland M. Cyberlindnera jadinii yeast as a protein source for broiler chickens: effects on growth performance and digestive function from hatching to 30 days of age. Poult Sci. 2020 Jun 1;99(6):3168-78.

8. Cruz A, Håkenåsen IM, Skugor A, Mydland LT, Åkesson CP, Hellestveit SS, et al. Candida utilis yeast as a protein source for weaned piglets: Effects on growth performance and digestive function. Livest Sci. 2019 Aug 1;226:31-9.

9. Lagos LV, Stein HH. Torula yeast has greater digestibility of amino acids and phosphorus, but not energy, compared with a commercial source of fish meal fed to weanling pigs. J Anim Sci. 2020 Jan 1;98(1).

10. Espinosa CD, Lagos LV, Stein HH. Effect of torula yeast on growth performance, diarrhea incidence, and blood characteristics in weanling pigs. J Anim Sci. 2020 Oct 1;98(10).

11. Gamboa-Delgado J, Fernández-Díaz B, Nieto-López M, Cruz-Suárez LE. Nutritional contribution of torula yeast and fish meal to the growth of shrimp Litopenaeus vannamei as indicated by natural nitrogen stable isotopes. Aquaculture. 2016;453:116-21.

12. Al-Hafedh YS, Alam A. Replacement of Fishmeal by Single Cell Protein Derived from Yeast Grown on Date (Phoenix dactylifera) Industry Waste in the Diet of Nile Tilapia (Oreochromis niloticus) Fingerlings. J Appl Aquac. 2013;25(4):346-58.

13. Øvrum Hansen J, Hofossæter M, Sahlmann C, Ånestad R, Reveco-Urzua FE, Press CML, et al. Effect of Candida utilis on growth and intestinal health of Atlantic salmon (Salmo salar) parr. Aquaculture. 2019 Sep 15;511.

14. Sahlmann C, Djordjevic B, Lagos L, Mydland LT, Morales-Lange B, Øvrum Hansen J, et al. Yeast as a protein source during smoltification of Atlantic salmon (Salmo salar L.), enhances performance and modulates health. Aquaculture. 2019;513(May):734396.

15. Øverland M, Skrede A. Yeast derived from lignocellulosic biomass as a sustainable feed resource for use in aquaculture. J Sci Food Agric. 2017 Feb 1;97(3):733-42.

16. Smárason BÖ, Alriksson B, Jóhannsson R. Safe and sustainable protein sources from the forest industry - The case of fish feed. Vol. 84 , Trends in Food Science and Technology. Elsevier Ltd; 2019. p. 12-4.

17. Solberg B, Moiseyev A, Hansen JØ, Horn SJ, Øverland M. Wood for food: Economic impacts of sustainable use of forest biomass for salmon feed production in Norway. For Policy Econ. 2021 Jan 1;122:102337.

18. Øverland M, Karlsson A, Mydland LT, Romarheim OH, Skrede A. Evaluation of Candida utilis, Kluyveromyces marxianus and Saccharomyces cerevisiae yeasts as protein sources in diets for Atlantic salmon (Salmo salar). Aquaculture. 2013 Jul 15;402-403:1-7.

19. Ugalde UO, Castrillo Jl. Single cell proteins from fungi and yeasts. Appl Mycol Biotechnol. 2002;2(C):123-49.

20. Cottrell RS, Blanchard JL, Halpern BS, Metian M, Froehlich HE. Global adoption of novel aquaculture feeds could substantially reduce forage fish demand by 2030. Nat Food. 2020 May 19;1(5):301-8.

21. Reveco-Urzua FE, Hofossæter M, Rao Kovi M, Mydland LT, Ånestad R, Sørby R, et al. Candida utilis yeast as a functional protein source for Atlantic salmon (Salmo salar L.): Local intestinal tissue and plasma proteome responses. Angers A, editor. PLoS One. 2019 Dec 30;14(12):e0218360.

22. Shurson GC. Yeast and yeast derivatives in feed additives and ingredients: Sources, characteristics, animal responses, and quantification methods. Vol. 235, Animal Feed Science and Technology. Elsevier B.V.; 2018. p. 60-76. 
23. López Nadal A, Ikeda-Ohtsubo W, Sipkema D, Peggs D, McGurk C, Forlenza M, et al. Feed, Microbiota, and Gut Immunity: Using the Zebrafish Model to Understand Fish Health. Vol. 11, Frontiers in Immunology. Frontiers Media S.A.; 2020. p. 114.

24. Gajardo K, Rodiles A, Kortner TM, Krogdahl Å, Bakke AM, Merrifield DL, et al. A high-resolution map of the gut microbiota in Atlantic salmon (Salmo salar): A basis for comparative gut microbial research. Sci Rep. 2016 Nov 3;6(1):30893.

25. Perry WB, Lindsay E, Payne CJ, Brodie C, Kazlauskaite R. The role of the gut microbiome in sustainable teleost aquaculture. Vol. 287, Proceedings of the Royal Society B: Biological Sciences. Royal Society Publishing; 2020.

26. Ghanbari M, Kneifel W, Domig KJ. A new view of the fish gut microbiome: Advances from next-generation sequencing. 2015;

27. Llewellyn MS, Boutin S, Hoseinifar SH, Derome N. Teleost microbiomes: The state of the art in their characterization, manipulation and importance in aquaculture and fisheries. Vol. 5, Frontiers in Microbiology. Frontiers Research Foundation; 2014. p. 1-1.

28. Daniel H. Diet and the gut microbiome: From hype to hypothesis. Br J Nutr. 2020;124(6):521-30.

29. Ingerslev H-C, Strube ML, Jørgensen L von G, Dalsgaard I, Boye M, Madsen L. Diet type dictates the gut microbiota and the immune response against Yersinia ruckeri in rainbow trout (Oncorhynchus mykiss). Fish Shellfish Immunol. 2014 Oct 1;40(2):624-33.

30. Llewellyn MS, McGinnity P, Dionne M, Letourneau J, Thonier F, Carvalho GR, et al. The biogeography of the atlantic salmon (Salmo salar) gut microbiome. ISME J. 2016 May;10(5):1280-4.

31. Dehler CE, Secombes CJ, Martin SAM. Seawater transfer alters the intestinal microbiota profiles of Atlantic salmon (Salmo salar L.). Sci Rep. 2017 $\operatorname{Dec} 24 ; 7(1): 13877$.

32. Gajardo K, Jaramillo-Torres A, Kortner TM, Merrifield DL, Tinsley J, Bakke AM, et al. Alternative protein sources in the diet modulate microbiota and functionality in the distal intestine of Atlantic salmon (Salmo salar). Appl Environ Microbiol. 2017 Mar 1;83(5).

33. Siriyappagouder P, Galindo-Villegas J, Lokesh J, Mulero V, Fernandes JMO, Kiron V. Exposure to yeast shapes the intestinal bacterial community assembly in zebrafish larvae. Front Microbiol. 2018 Aug 14;9(AUG):1868.

34. Rodríguez JM, Murphy K, Stanton C, Ross RP, Kober Ol, Juge N, et al. The composition of the gut microbiota throughout life, with an emphasis on early life. Microb Ecol Health Dis. 2015 Feb 2;26(1):26050.

35. Michl SC, Ratten J-M, Beyer M, Hasler M, LaRoche J, Schulz C. The malleable gut microbiome of juvenile rainbow trout (Oncorhynchus mykiss): Diet-dependent shifts of bacterial community structures. PLoS One. 2017;12(5):e0177735.

36. Michl SC, Beyer M, Ratten J-M, Hasler M, LaRoche J, Schulz C. A diet-change modulates the previously established bacterial gut community in juvenile brown trout (Salmo trutta). Sci Rep. 2019 Dec 20;9(1):2339.

37. Ring $\varnothing$ E, Hoseinifar SH, Ghosh K, Doan H Van, Beck BR, Song SK. Lactic acid bacteria in finfish-An update. Vol. 9, Frontiers in Microbiology. Frontiers Media S.A.; 2018. p. 1818.

38. Talwar C, Nagar S, Lal R, Negi RK. Fish Gut Microbiome: Current Approaches and Future Perspectives. Vol. 58, Indian Journal of Microbiology. Springer; 2018. p. 397-414.

39. Wang C, Sun G, Li S, Li X, Liu Y. Intestinal microbiota of healthy and unhealthy Atlantic salmon Salmo salar L. in a recirculating aquaculture system. J Oceanol Limnol. 2018 Mar 1;36(2):414-26.

40. Huyben D, Nyman A, Vidaković A, Passoth V, Moccia R, Kiessling A, et al. Effects of dietary inclusion of the yeasts Saccharomyces cerevisiae and Wickerhamomyces anomalus on gut microbiota of rainbow trout. Aquaculture. $2017 \mathrm{Apr}$ 20;473:528-37.

41. lakhno S, Umu ÖCO, Håkenåsen IM, Åkesson CP, Mydland LT, Press CM, et al. Effect of Cyberlindnera jadinii yeast as a protein source on intestinal microbiota and butyrate levels in post-weaning piglets. 2020;

42. Klindworth A, Pruesse E, Schweer T, Peplies J, Quast C, Horn M, et al. Evaluation of general 16S ribosomal RNA gene PCR primers for classical and next-generation sequencing-based diversity studies. Nucleic Acids Res. 2013;41(1):1-11.

43. Bates, D. Maechler, M. Bolker, B. Walker S. Fitting Linear Mixed-Effects Models Using Ime4. 2015.

44. Pinheiro J, Bates D, DebRoy S, Sarkar D RCT. nlme: Linear and Nonlinear Mixed Effects Models. 2020.

45. Callahan BJ, McMurdie PJ, Rosen MJ, Han AW, Johnson AJA, Holmes SP. DADA2: High-resolution sample inference from Illumina amplicon data. Nat Methods. 2016 Jun 29;13(7):581-3.

46. Team Rs. RStudio: Integrated Development for R. RStudio, PBC, Boston, MA URL http://www.rstudio.com/. 2020.

47. Quast C, Pruesse E, Yilmaz P, Gerken J, Schweer T, Yarza P, et al. The SILVA ribosomal RNA gene database project: Improved data processing and web-based tools. Nucleic Acids Res. 2013 Jan 1;41(D1).

48. McMurdie PJ, Holmes S. Phyloseq: An R Package for Reproducible Interactive Analysis and Graphics of Microbiome Census Data. PLoS One. 2013 Apr 22;8(4).

49. Lahti L, Shetty S. Microbiome. 2017.

50. Oksanen J, Blanchet, G F, Friendly M, Kint R, Legendre P, McGlinn D, et al. Community Ecology. 2020.

51. Wickham. H. ggplot2: Elegant Graphics for Data Analysis. Springer-Verlag New York; 2016.

52. Fox J, Weisberg S, Adler D, Bates D, Baud-Bovy G, Ellison S. An R Companion to Applied Regression [Internet]. R Topics Documented, second edition. 2011 [cited 2020 Nov 4]. Available from: https://books.google.is/books?

Page $10 / 20$ 
$\mathrm{hl}=$ en\&lr=\&id=uPNrDwAAQBAJ\&oi=fnd\&pg=PP1\&ots=MwE49G7s46\&sig=5nJTplopT9X8AayaQoK2NA8beBM\&redir_esc=y\#v=onepage\&q\&f=false

53. Herbinger CM, Friars GW. Correlation between condition factor and total lipid content in Atlantic salmon, Salmo salar L., parr. Aquac Res. 1991 Dec 1;22(4):527-9.

54. Olvera-Novoa MA, Martínez-Palacios CA, Olivera-Castillo L. Utilization of torula yeast ( Candida utilis ) as a protein source in diets for tilapia ( Oreochromis mossambicus Peters) fry. Aquac Nutr. 2002 Dec 1;8(4):257-64.

55. Lavoie C, Courcelle M, Redivo B, Derome N. Structural and compositional mismatch between captive and wild Atlantic salmon (Salmo salar) parrs' gut microbiota highlights the relevance of integrating molecular ecology for management and conservation methods. Evol Appl. 2018 Oct 1;11(9):1671-85.

56. Shade A. Diversity is the question, not the answer. Vol. 11, ISME Journal. Nature Publishing Group; 2017. p. 1-6.

57. Webster TMU, Consuegra S, Leaniz CG de. Early life stress causes persistent impacts on the microbiome of Atlantic salmon. bioRxiv. 2020;2020.01.16.908939.

58. Catalán N, Villasante A, Wacyk J, Ramírez C, Romero J. Fermented Soybean Meal Increases Lactic Acid Bacteria in Gut Microbiota of Atlantic Salmon (Salmo salar). Probiotics Antimicrob Proteins. 2018 Sep 1;10(3):566-76.

59. Huyben D. Effects of feeding yeasts on blood physiology and gut microbiota of rainbow trout.

60. Nyman A, Huyben D, Lundh T, Dicksved J. Effects of microbe- and mussel-based diets on the gut microbiota in Arctic charr (Salvelinus alpinus). Aquac Reports. 2017 Feb 1;5:34-40.

61. Rimoldi S, Gini E, Koch JFA, lannini F, Brambilla F, Terova G. Effects of hydrolyzed fish protein and autolyzed yeast as substitutes of fishmeal in the gilthead sea bream (Sparus aurata) diet, on fish intestinal microbiome. BMC Vet Res. 2020 Apr 22;16(1):118.

62. Liu H, Li J, Guo X, Liang Y, Wang W. Yeast culture dietary supplementation modulates gut microbiota, growth and biochemical parameters of grass carp. Microb Biotechnol. 2018 May 1;11(3):551-65.

63. Villasante A, Ramírez C, Catalán N, Opazo R, Dantagnan P, Romero J. Effect of Dietary Carbohydrate-to-Protein Ratio on Gut Microbiota in Atlantic Salmon (Salmo salar). Animals. 2019 Mar 11;9(3):89.

64. Dehler CE, Secombes CJ, Martin SAM. Environmental and physiological factors shape the gut microbiota of Atlantic salmon parr (Salmo salar L.). Aquaculture. 2017 Jan 20;467:149-57.

65. Askarian F, Zhou Z, Olsen RE, Sperstad S, Ring $\varnothing$ E. Culturable autochthonous gut bacteria in Atlantic salmon (Salmo salar L.) fed diets with or without chitin. Characterization by 16S rRNA gene sequencing, ability to produce enzymes and in vitro growth inhibition of four fish pathogens. Aquaculture. 2012 Jan 25;326-329:1-8.

66. Ring $\varnothing$ E, Zhou Z, Vecino JLG, Wadsworth S, Romero J, Krogdahl, et al. Effect of dietary components on the gut microbiota of aquatic animals. A never-ending story? Aquac Nutr. 2016 Apr 1;22(2):219-82.

67. Ring $\varnothing$ E, Strøm E, Tabachek J-A. Intestinal microflora of salmonids: a review. Aquac Res. 1995 Oct 1;26(10):773-89.

68. NRC. Nutrient requirements of fish and shrimp. National Research Council of the National Academies. National academies press; 2011.

69. Simpson HL, Campbell BJ. Review article: Dietary fibre-microbiota interactions. Aliment Pharmacol Ther. 2015 Jul 1;42(2):158-79.

70. Merrifield DL, Balcázar JL, Daniels C, Zhou Z, Carnevali O, Sun Y-Z, et al. Indigenous Lactic Acid Bacteria in Fish and Crustaceans. In: Aquaculture Nutrition. Chichester, UK: John Wiley \& Sons, Ltd; 2014. p. 128-68.

71. Chapagain P, Arivett B, Cleveland BM, Walker DM, Salem M. Analysis of the fecal microbiota of fast-and slow-growing rainbow trout (Oncorhynchus mykiss). BMC Genomics. 2019 Oct 29;20(1):788.

\section{Tables}

Table 1. Feed formulation and chemical composition for marine protein (FM) feed treatments. 


\begin{tabular}{|c|c|c|c|}
\hline Formulation $\left(g \mathrm{~kg}^{-1}\right)$ & $\mathrm{FM} 0 \%$ & FM10\% & FM20\% \\
\hline Fish Meal ${ }^{a}$ & 676.8 & 610.0 & 542.9 \\
\hline Pre-gelatinised Wheat ${ }^{b}$ & 209.7 & 172.9 & 136.2 \\
\hline Vitamin-Mineral Premix ${ }^{c}$ & 10.0 & 10.0 & 10.0 \\
\hline Fish Oil ${ }^{a}$ & 103.5 & 107.1 & 110.8 \\
\hline Torula yeast (Cyberlindnera jadinii) & 0.0 & 100.0 & 200.0 \\
\hline \multicolumn{4}{|l|}{ Analysed Content $\left(g \mathrm{~kg}^{-1}\right)$} \\
\hline Dry Matter & 935 & 932 & 936 \\
\hline Crude Protein & 506 & 502 & 507 \\
\hline Crude Lipid & 162 & 165 & 170 \\
\hline Ash & 103 & 100 & 97 \\
\hline \multicolumn{4}{|l|}{ Essential Amino Acids $\left(g \mathrm{~kg}^{-1}\right)$} \\
\hline Arginine & 22.2 & 27.6 & 27.9 \\
\hline Histidine & 9.3 & 11.5 & 11.6 \\
\hline Isoleucine & 15.7 & 19.9 & 20.7 \\
\hline Leucine & 29.3 & 36.4 & 37.2 \\
\hline Lysine & 29.7 & 37.4 & 37.2 \\
\hline Methionine & 12.1 & 12.8 & 11.3 \\
\hline Phenylalanine & 15.5 & 19.4 & 19.6 \\
\hline Threonine & 17.4 & 21.4 & 22.2 \\
\hline Valine & 19.5 & 24.4 & 25.4 \\
\hline Tryptophan & 5.5 & 5.5 & 5.2 \\
\hline \multicolumn{4}{|l|}{ Non-Essential Amino Acids $\left(g \mathrm{~kg}^{-1}\right)$} \\
\hline Alanine & 23.6 & 29.2 & 30.6 \\
\hline Aspartic acid & 36.1 & 43.8 & 44.9 \\
\hline Glycine & 24.9 & 30.3 & 30.6 \\
\hline Glutamic acid & 56.0 & 69.8 & 70.5 \\
\hline Cystein + Cysteine & 4.5 & 5.3 & 5.2 \\
\hline Tyrosine & 12.6 & 15.7 & 15.8 \\
\hline Proline & 17.0 & 21.7 & 19.4 \\
\hline Serine & 17.2 & 21.3 & 22.4 \\
\hline
\end{tabular}

a Laxá hf. Krossanes, Iceland

${ }^{\mathrm{b}}$ Emmelev A/S, Denmark

${ }^{c}$ Laxa salmon premix 2006 1\%, Trouw Nutrition, The Netherlands

Table 2. Feed formulation and chemical composition for marine and plant protein combined (MIX) feed treatments. 


\begin{tabular}{|c|c|c|c|}
\hline Formulation $\left(\mathrm{g} \mathrm{kg}^{-1}\right)$ & MIX0\% & MIX10\% & MIX20\% \\
\hline Fish Meal $^{a}$ & 425.0 & 425.0 & 425.0 \\
\hline Pre-gelatinised Wheat ${ }^{b}$ & 191.1 & 159.4 & 127.7 \\
\hline Corn Gluten Meal ${ }^{a}$ & 72.5 & 53.2 & 33.9 \\
\hline Vitamin-Mineral Premix ${ }^{c}$ & 10.0 & 10.0 & 10.0 \\
\hline Fish Oil a & 116.7 & 116.8 & 117.0 \\
\hline Torula yeast (Cyberlindnera jadinii) & 0.0 & 100.0 & 200.0 \\
\hline Lysine-HCl & 8.6 & 6.0 & 3.4 \\
\hline DL-Methionine & 0.4 & 0.7 & 1.0 \\
\hline Soy Protein Concentrate ${ }^{a}$ & 75.7 & 55.5 & 35.4 \\
\hline Wheat Gluten Meal a & 100.0 & 73.3 & 46.7 \\
\hline \multicolumn{4}{|l|}{ Analysed Content, $\left(\mathrm{g} \mathrm{kg}^{-1}\right)$} \\
\hline Dry Matter & 942 & 918 & 935 \\
\hline Crude Protein & 515 & 495 & 506 \\
\hline Crude Lipid & 154 & 162 & 161 \\
\hline Ash & 79 & 80 & 86 \\
\hline \multicolumn{4}{|l|}{ Essential Amino Acids $\left(g \mathrm{~kg}^{-1}\right)$} \\
\hline Arginine & 25.7 & 23.5 & 31.7 \\
\hline Histidine & 11.5 & 10.1 & 11.6 \\
\hline Isoleucine & 20.1 & 17.6 & 20.8 \\
\hline Leucine & 41.1 & 35.3 & 39.0 \\
\hline Lysine & 34.4 & 29.4 & 32.7 \\
\hline Methionine & 11.9 & 11.1 & 11.4 \\
\hline Phenylalanine & 20.8 & 18.7 & 21.4 \\
\hline Threonine & 19.6 & 17.7 & 20.6 \\
\hline Valine & 23.6 & 21.2 & 25.3 \\
\hline Tryptophan & 5.2 & 5.2 & 5.6 \\
\hline \multicolumn{4}{|l|}{ Non-Essential Amino Acids $\left(g \mathrm{~kg}^{-1}\right)$} \\
\hline Alanine & 28.0 & 25.0 & 29.9 \\
\hline Aspartic acid & 40.4 & 36.0 & 43.4 \\
\hline Glycine & 26.4 & 24.1 & 28.2 \\
\hline Glutamic acid & 92.9 & 77.7 & 81.4 \\
\hline Cystein + Cysteine & 6.2 & 6.1 & 6.1 \\
\hline Tyrosine & 16.6 & 14.1 & 17.4 \\
\hline Proline & 29.5 & 24.6 & 23.6 \\
\hline Serine & 22.4 & 19.8 & 23.4 \\
\hline
\end{tabular}

Page 13/20 
a Laxá hf. Krossanes, Iceland

${ }^{\mathrm{b}}$ Emmelev A/S, Denmark

${ }^{c}$ Laxa salmon premix 2006 1\%, Trouw Nutrition, The Netherlands

Table 3. Chemical composition of the protein sources used in feed treatments of this study.

\begin{tabular}{|c|c|c|c|c|c|}
\hline & Raw Protein Materials & & & & \\
\hline Composition $\left(g k g^{-1}\right)$ & $\begin{array}{l}\text { Torula yeast (Cyberlindnera } \\
\text { jadinii) }\end{array}$ & $\begin{array}{l}\text { Fish } \\
\text { meal }\end{array}$ & $\begin{array}{l}\text { Soy protein } \\
\text { concentrate }\end{array}$ & $\begin{array}{l}\text { Corn gluten } \\
\text { meal }\end{array}$ & $\begin{array}{l}\text { Wheat gluten } \\
\text { meal }\end{array}$ \\
\hline Dry Matter & 938.0 & 909.0 & 925.0 & 910.0 & 922.0 \\
\hline Crude Protein & 514.0 & 659.0 & 633.0 & 582.0 & 742.0 \\
\hline Crude Lipid & 25.1 & 107.0 & 2.0 & 10.0 & 16.0 \\
\hline Ash & 88.4 & 139.0 & 90.0 & 23.0 & 11.0 \\
\hline \multicolumn{6}{|c|}{ Essential Amino Acids $\left(g k g^{-1}\right)$} \\
\hline Arginine & 30.8 & 42.3 & 42.9 & 18.6 & 25.0 \\
\hline Histidine & 8.9 & 18.2 & 15.5 & 12.2 & 14.0 \\
\hline Isoleucine & 20.2 & 30.2 & 27.5 & 23.2 & 24.5 \\
\hline Leucine & 32.0 & 57.1 & 47.4 & 96.1 & 48.3 \\
\hline Lysine & 34.2 & 58.8 & 37.0 & 9.1 & 11.4 \\
\hline Methionine & 5.3 & 19.6 & 9.0 & 14.3 & 11.8 \\
\hline Phenylalanine & 18.6 & 28.9 & 32.1 & 37.2 & 35.7 \\
\hline Threonine & 22.9 & 33.3 & 25.1 & 20.3 & 17.8 \\
\hline Valine & 26.0 & 37.8 & 28.5 & 28.0 & 27.4 \\
\hline Tryptophan & 5.8 & 7.6 & 8.6 & 3.1 & 7.5 \\
\hline \multicolumn{6}{|c|}{$\begin{array}{l}\text { Non-Essential Amino Acids ( } g \\
\mathrm{~kg}^{-1} \text { ) }\end{array}$} \\
\hline Alanine & 28.4 & 47.2 & 26.3 & 52.7 & 18.1 \\
\hline Aspartic acid & 39.8 & 69.2 & 71.3 & 36.2 & 21.9 \\
\hline Glycine & 21.3 & 50.3 & 25.6 & 17.4 & 23.3 \\
\hline Glutamic acid & 66.1 & 105.0 & 114.0 & 130.0 & 260.0 \\
\hline Cysteine (+ Cysteine) & 3.3 & 5.8 & 8.6 & 11.4 & 15.5 \\
\hline Tyrosine & 16.1 & 24.6 & 22.3 & 30.6 & 22.9 \\
\hline Proline & 15.0 & 32.1 & 30.9 & 55.7 & 86.9 \\
\hline Serine & 21.0 & 32.6 & 32.4 & 33.5 & 34.7 \\
\hline
\end{tabular}

\section{Figures}


a

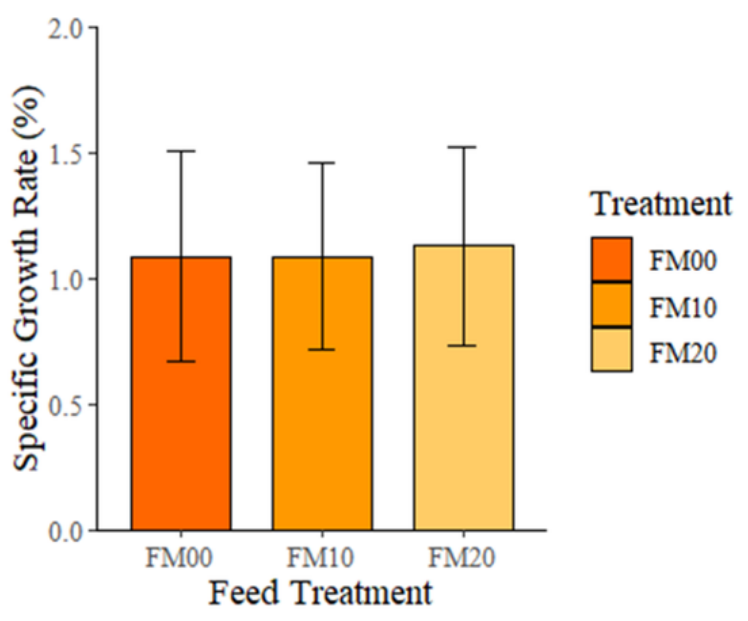

c

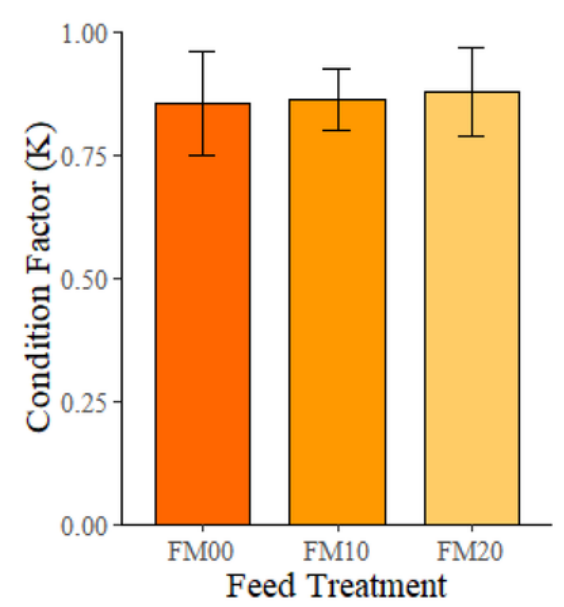

Treatment

\begin{tabular}{|l}
$\square$ FM00 \\
FM10 \\
FM20
\end{tabular} b
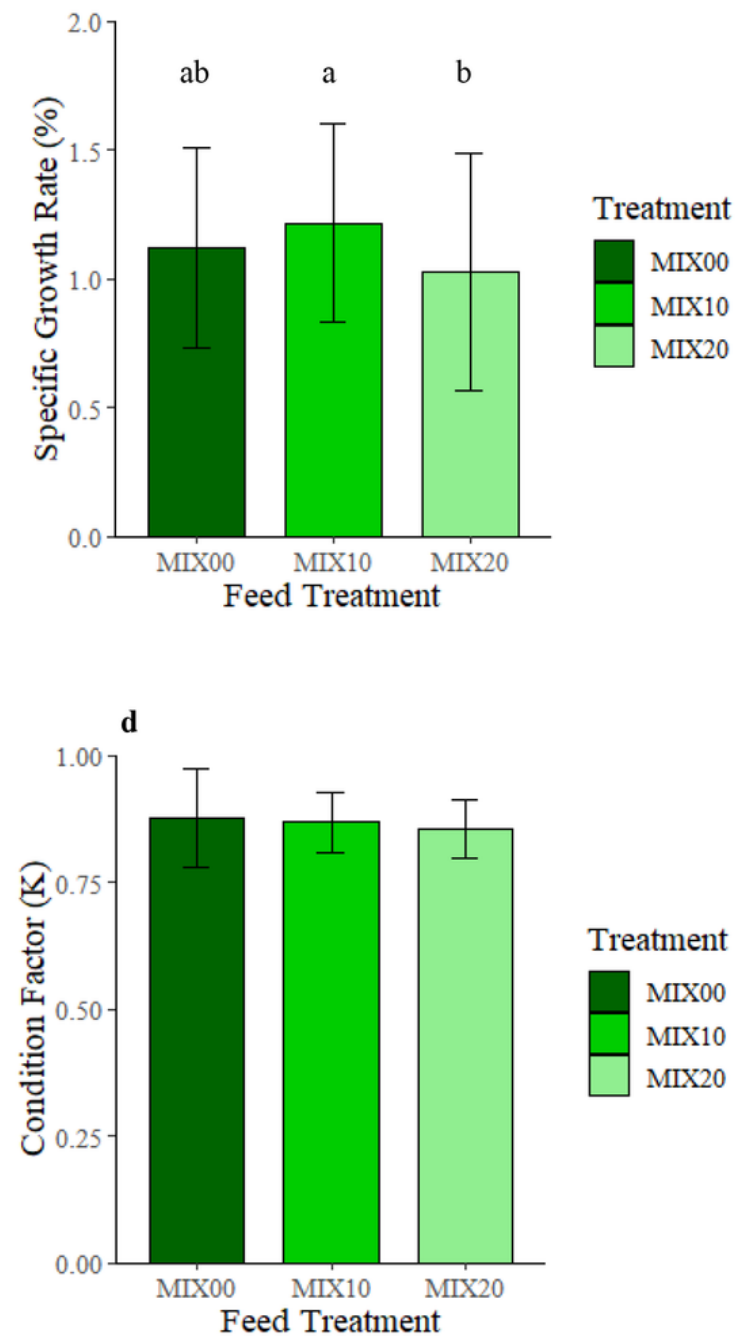

\section{Figure 1}

Bar plots of the Specific Growth Rate (\%) for (a) FM feed treatments and (b) MIX feed treatments, and bar plots of the Condition Factor (K) for (c) FM feed treatments and (d) MIX feed treatments. Bars represent the standard deviation of the data and different lowercase letters indicate significantly different means $(P<0.05)$. 


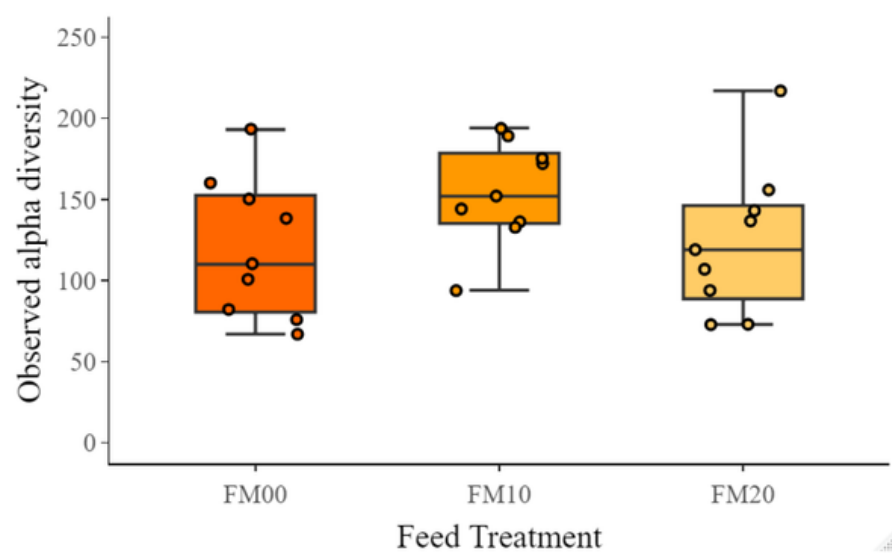

c

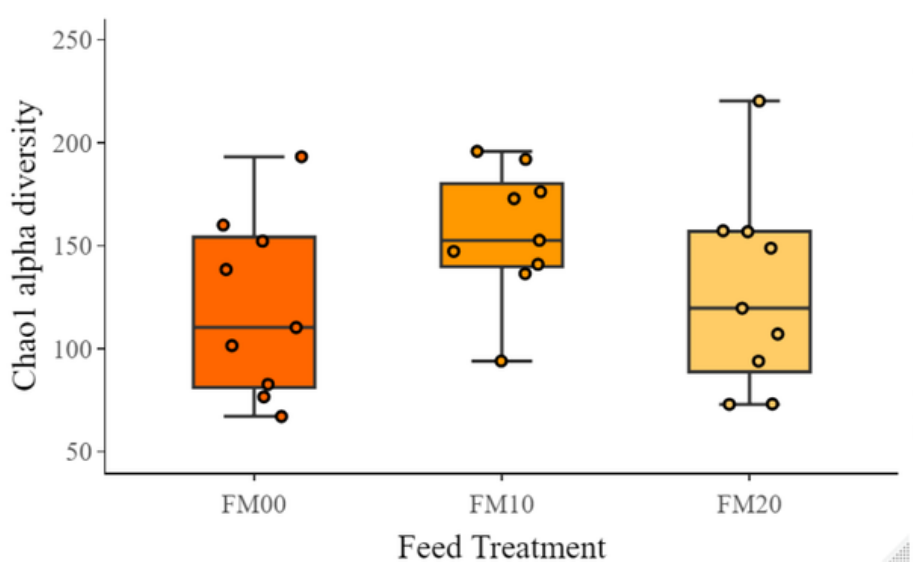

b

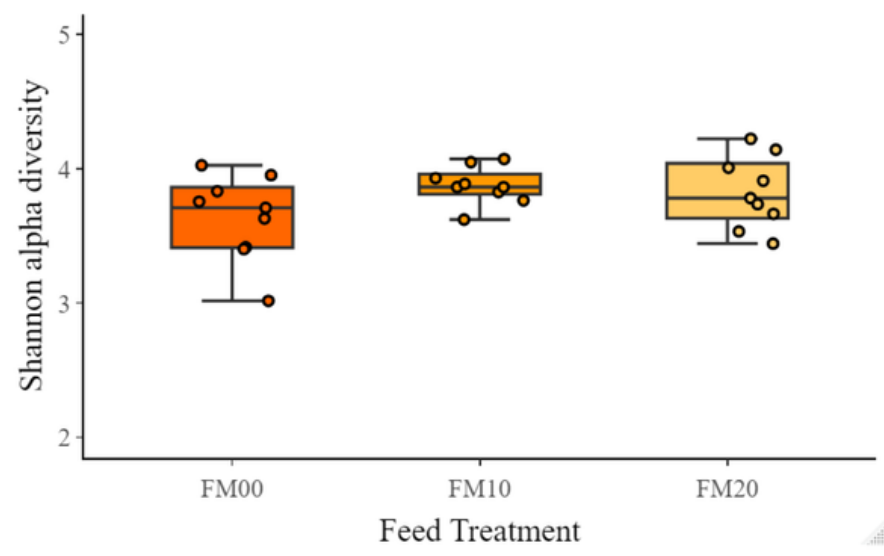

d

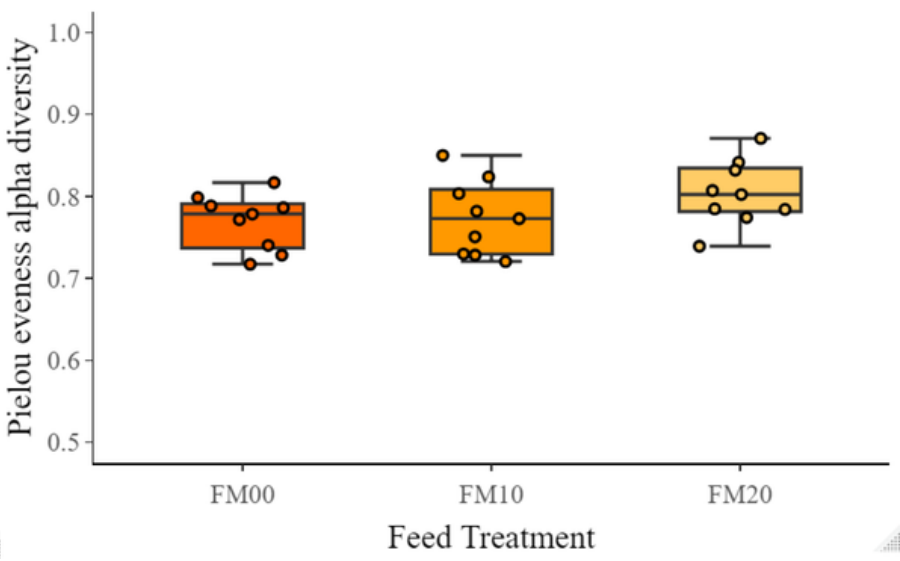

Figure 2

Box plots of alpha diversity measures for the FM Feed Treatments a) The observed diversity, b) Shannon diversity, c) Chao1 diversity, d) Pielou's evenness. 


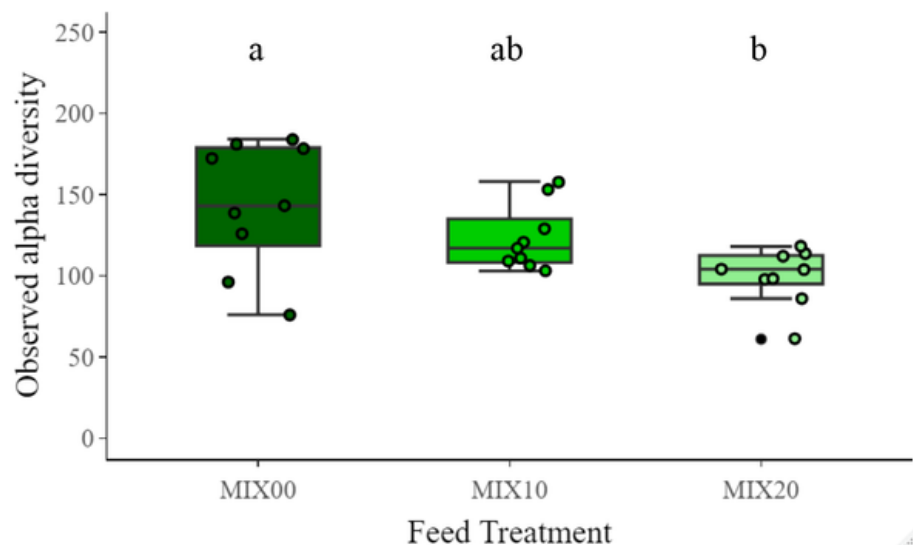

c

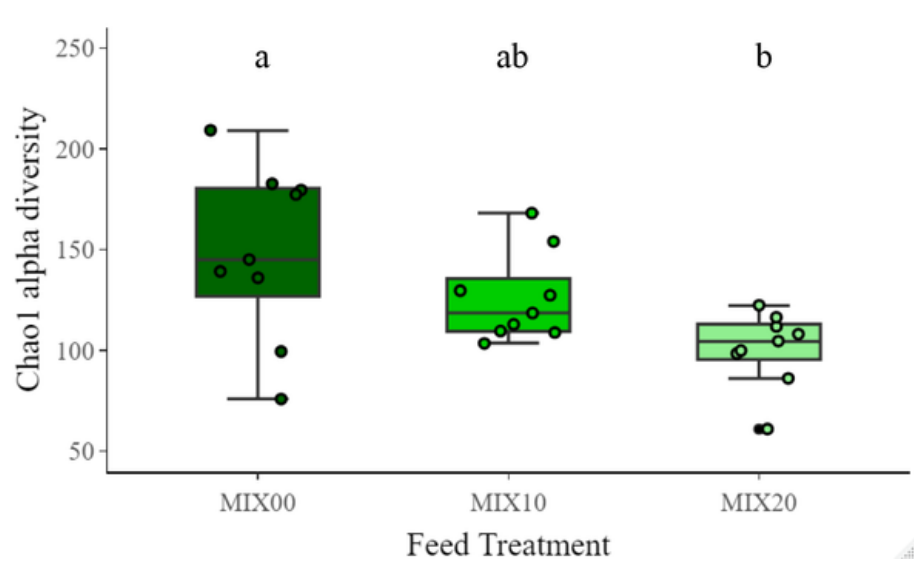

b

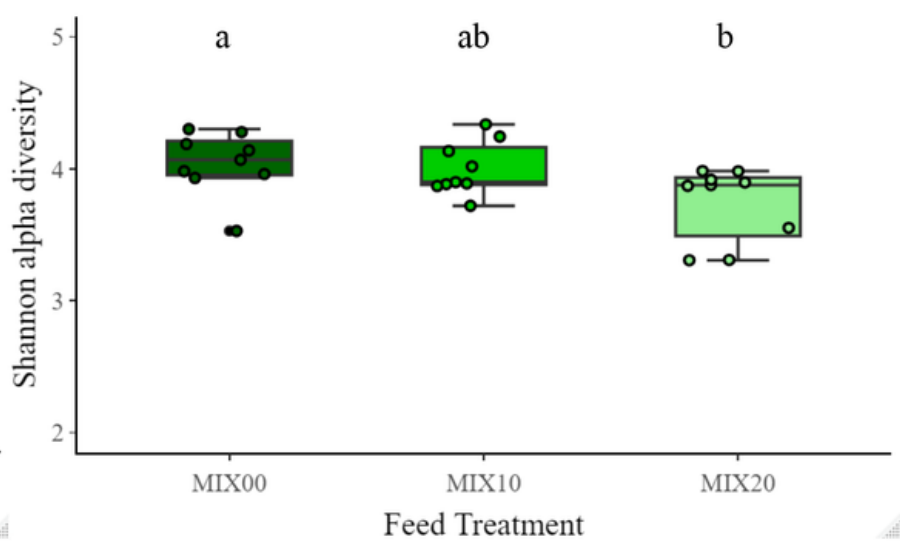

d

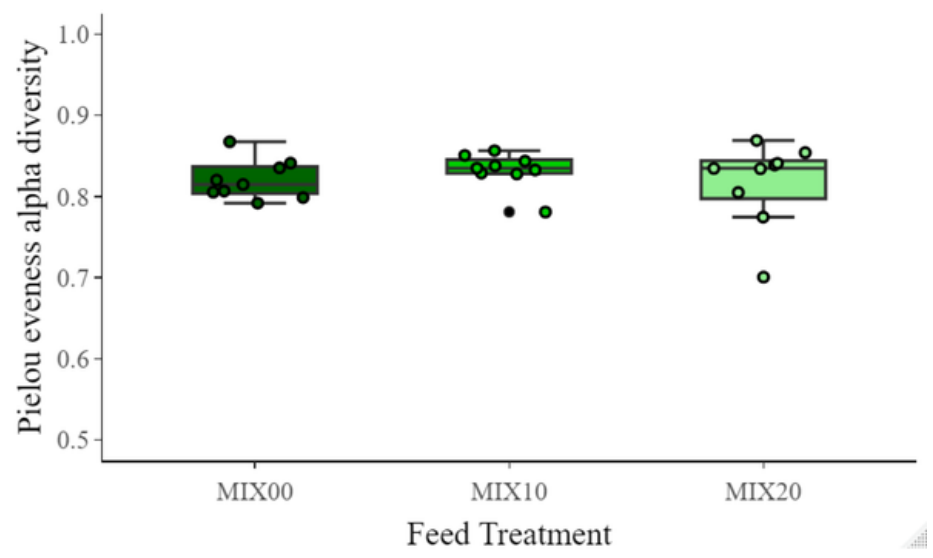

Figure 3

Box plots of alpha diversity measures for the MIX Feed Treatments a) The observed diversity, b) Shannon diversity, c) Chao1 diversity, d) Pielou's evenness. Different lowercase letters indicate significantly different means $(P<0.05)$.

a

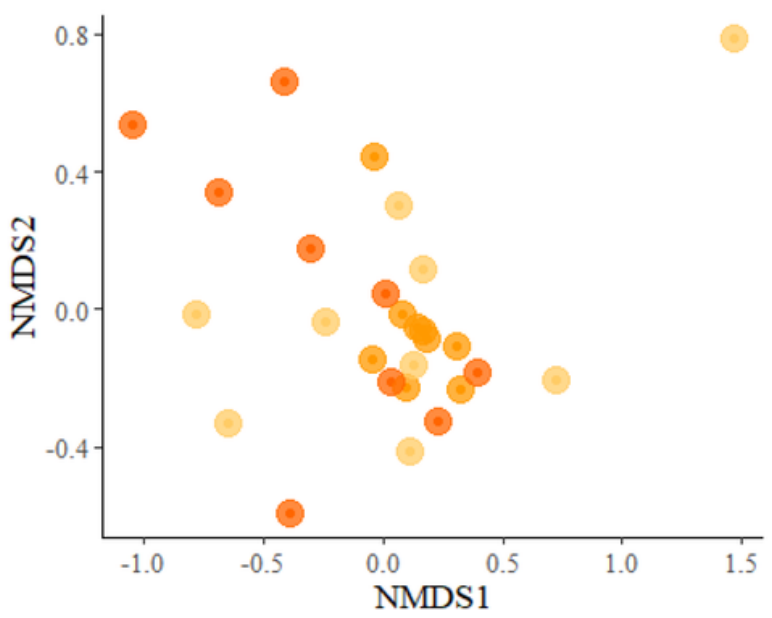

b

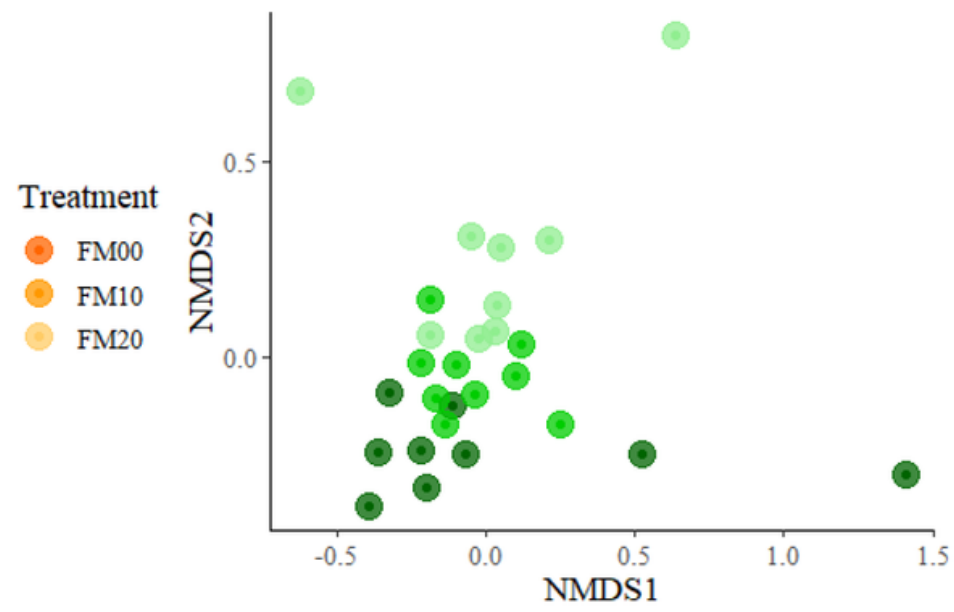

Treatment

- MIX00

- MIX10

MIX20

Figure 4 
Non-metric multidimension scaling (NMDS) of fish from a) FM feed treatments b) MIX feed treatments. Each point represents a single fish and colour indicates the feed treatment inclusion level.

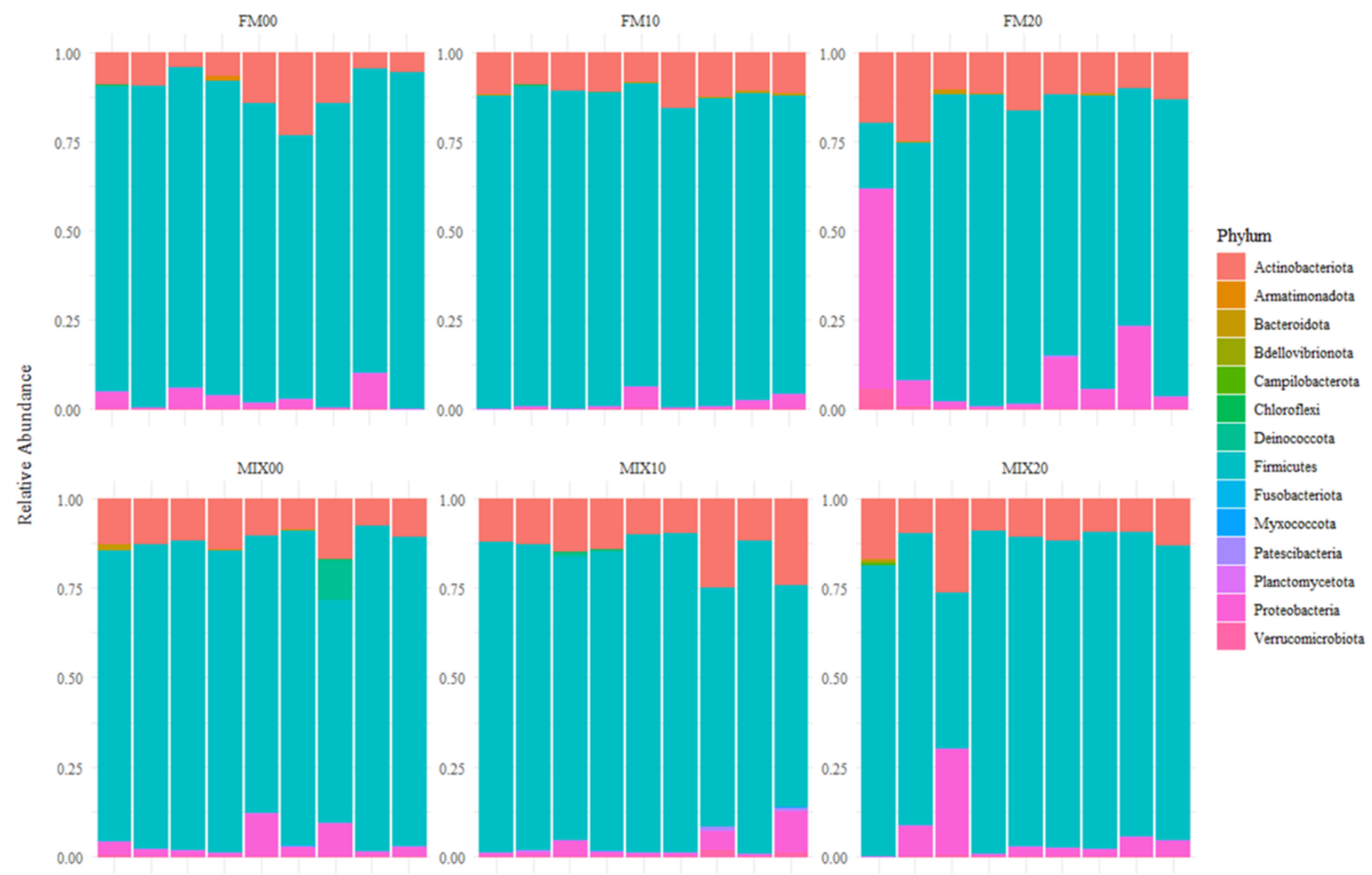

\section{Figure 5}

Stacked bar plot of gut bacterial composition using Relative Abundance of the most common phyla for fish from FM diets and fish from MIX diets. 


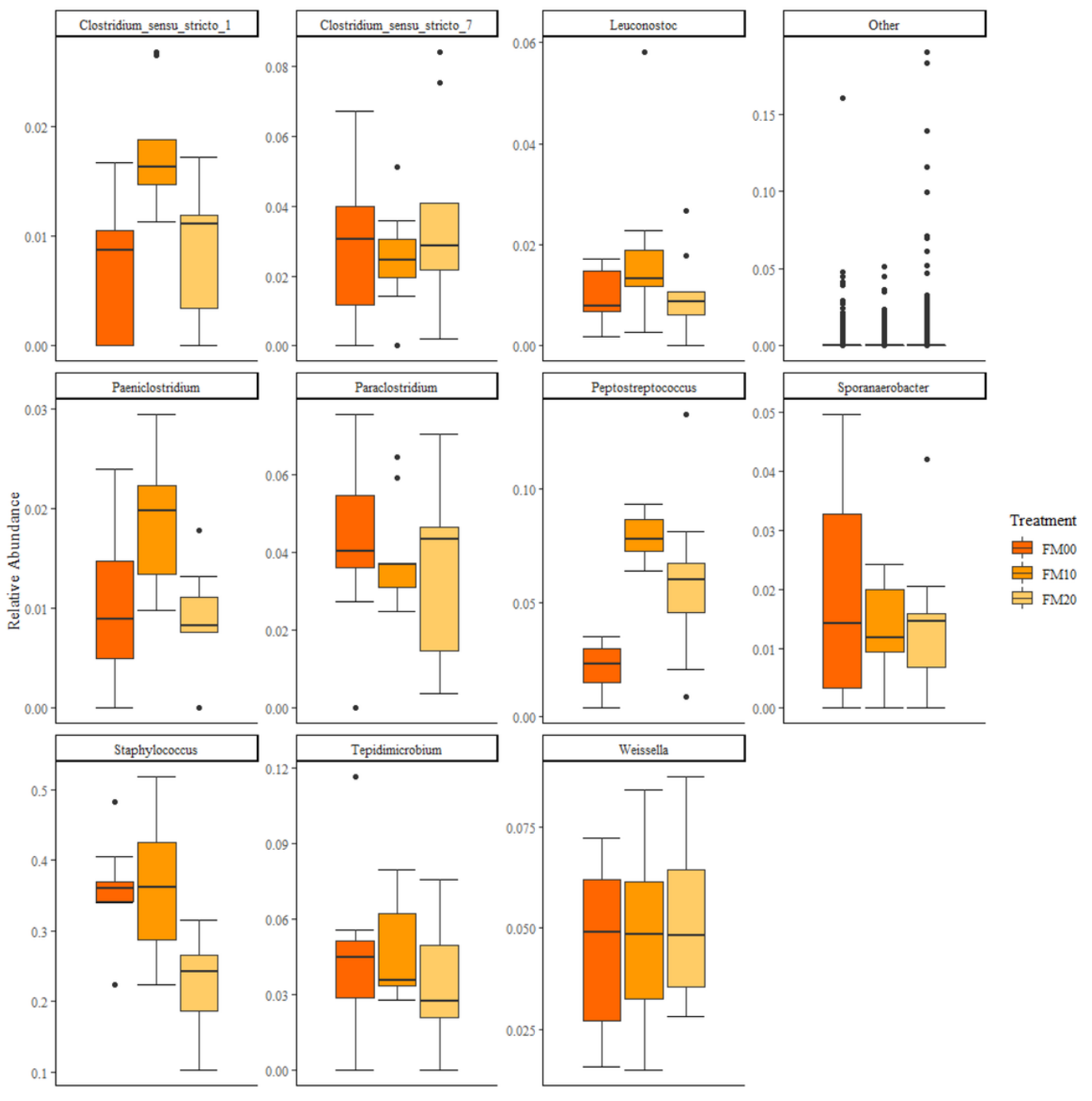

Figure 6

Boxplots of gut bacterial composition using Relative Abundance of the most common genera for FM diets. 


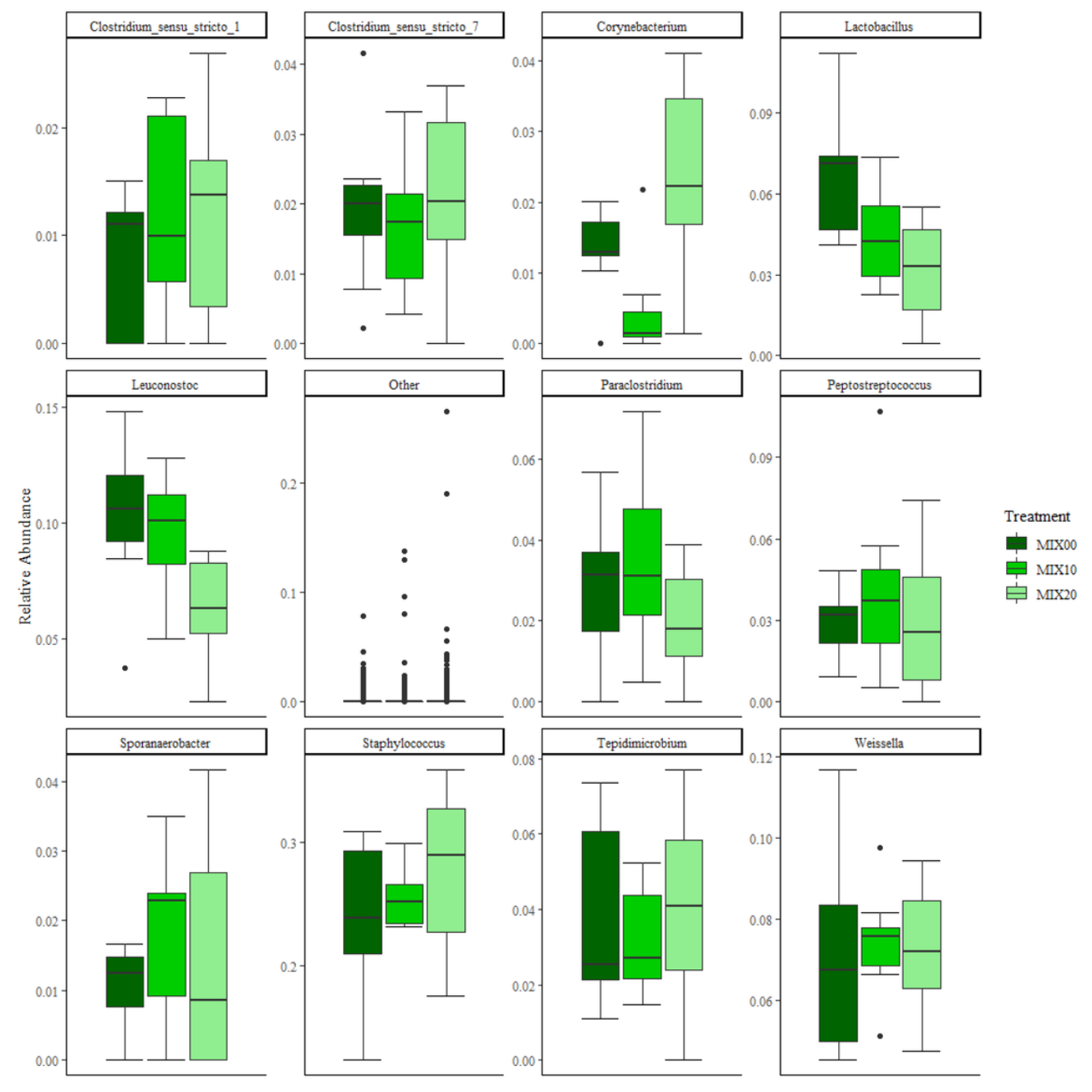

Figure 7

Boxplots of gut bacterial composition using Relative Abundance of the most common genera for MIX diets. 